\title{
Dislocation rate fallowing posterior total hip arthroplasty with intra-osseous soft tissue repair
}

\begin{abstract}
Background: The commonly used approaches for THR include; Anterior Approaches. (Smith-Petersen); Anterio-lateral approaches; Posterior Approaches. (Osborne, \& Moore); Medial Approach (Ferguson; Hoppenfeld and deBoer); Posterolateral Approach (Gibson); \& Lateral Approaches (Watson-Jones, Harris, McFarland and Osborne, Hardinge, Hay as described by McLauchlan). ${ }^{1}$ Posterior approach to the hip is famous to associated with higher dislocation rate of $4.5 \%{ }^{2}$ compare to $0.0 \%$ for the anterior approach. Other surgeon describe the marked reduction in the rates fallowing tissue repair from $6.38 \%$ to $0.0 \%{ }^{2,3} \mathrm{We}$ conduct the study design to determine dislocation rate following total hip arthroplasty using posterior approach and intra-osseous repairs of short rotators
\end{abstract}

Patient \& methods: A prospective, descriptive, hospital based longitudinal study design is conducted in Elribat University Hospital from June 2013 to June 2014 in which all patient operated for THA via posterior approach using intra-osseous soft tissue repair with size 2 nylon during study duration in Elribat University Hospital is included in study. Patients fallowed 6 month postoperatively using Harris hip score.

Results: The study includes 31 hips. Four patients were lost to follow up due to; death (cardiac disease 3 rd week post-operative), deep infection ( $7^{\text {th }}$ post-operative day) \& loss of contact. So the total remaining number were 27 hips with; 17 male $(62.96 \%) \& 10$ female $(37.04 \%)$. The analysis of data shows that no reported hip dislocation.

Conclusion: The high dislocation rate fallowing THR via posterior approach is markedly reduce if it fallowed by proper soft tissue repair to greater trochanter using strong suture.

Keywords: Arthroplasty, Diarthrodial joint, Acetabulum, Posterior, Anterior, Langenbeck
Volume 8 Issue 4 - 2017

\author{
Sakher Alssayed Mohamedahmed \\ Alwahbany,' Mahjoob Hamid Elkadagri, ${ }^{2}$ \\ Areeg Dawoud Hussien ${ }^{3}$ \\ 'General Orthopedic surgeon, Elzaeim Elazhary University, \\ Sudan \\ ${ }^{2}$ Arthroplasty Surgeon, Elribat University Hospital, Sudan \\ ${ }^{3}$ Medical Officer, $\mathrm{MOH}$, Sudan
}

Correspondence: Sakher Alssayed Mohamed Ahmed Alwahbany, Orthopedic Surgeon \& Anatomist, Alzaeim Alazhary University, Sudan, Tel 250000000000; Email sakherwahabany123@gmail.com

Received: May 16, 2017| Published: July 17, 2017

\section{Abbreviations}

THR, Total Hip Replacement; AVN, A Vascular Necrosis; OA, Osteo-Arthritis; THA, Total Hip Arthroplasty; DVT, Deep Vein Thrombosis; DHS, Dynamic Hip Screw

\section{Introduction}

The hip joint is a spheroidal, ball-and-socket type of diarthrodial joint. Its stability is based primarily on the bony architecture. The acetabulum is deepened by the fibro-cartilaginous labrum. The joint capsule extends anteriorly across the femoral neck to the trochanteric crest; however, it extends posteriorly only partially across the femoral neck, leaving the basocervical and intertrochanteric crest regions extracapsular. Three ligaments compose the capsule anteriorly. The iliofemoral ligament (Y ligament of Bigelow) is the strongest ligament in the body and attaches the anterior inferior iliac spine to the intertrochanteric line in an inverted $\mathrm{Y}$ fashion. The remaining anterior ligaments, the ischiofemoral and pubofemoral ligaments are weaker but lend additional stability. Inside the joint, the ligamentum teres arises from the apex of the cotyloid notch and attaches to the fovea of the femoral head. It transmits an arterial branch of the posterior division of the obturator artery to the femoral head (less significant in adults). ${ }^{4}$

Many diseases may affect the hip joint including developmental abnormality; developmental dysplasia of the hip, Acetabular dysplasia, traumatic; dislocation \& fractures, tumor, degenerative disease; osteoarthritis, inflammatory; septic arthritis , rheumatoid arthritis, etc. Many of this disease may cause total joint destruction that may necessitate joint replacement. ${ }^{5}$ The earliest recorded attempts at hip replacement (Gluck T, 1891), which were carried out in Germany, used ivory to replace the femoral head (the ball of the femur). ${ }^{6}$

Total hip replacement has been practiced widely in our country Sudan for approximately more than 10 years and the overall rate of THR is increasing over time. It is thought that the demand for primary THRs will continue to increase as disease of the hip is age related and life expectancy is increasing. Many variations have evolved in the surgical approaches and techniques used for total hip arthroplasty. They differ chiefly as to whether the patient is operated on in the lateral or supine position, and whether the hip is dislocated anteriorly or posteriorly. ${ }^{7}$ The common used approaches include; Anterior Approaches. (Smith-Petersen); Anterio-lateral approaches. (Smith-Petersen); Posterior Approaches, (Osborne, \& Moore); Medial Approach (Ferguson; Hoppenfeld and deBoer); Posterolateral Approach (Gibson); \& Lateral Approaches (WatsonJones, Harris, McFarland and Osborne, Hardinge, Hay as described by McLauchlan). ${ }^{7}$

\section{Posterior approach to the hip (moore or southern) [7]}

Posterior approach was first described by Langenback in 1874, for the purpose of draining pyoarthroses of the hip. The approach was later modified by Kocher and others, and then popularized in North America by Gibson. Moore advocated the use of a more inferiorly placed incision into the buttock to insert femoral endo-prostheses, and the approach was thus named "Southern Exposure. ${ }^{3}$

It provides exposure to acetabulum \& proximal femur \& Indicated in THA, hip hemiarthroplasty, removal of loose bodies, dependant drainage of septic hip, \& pedicle bone grafting. It can be extended into Kocher-Langenbeck incision for extensive Acetabular surgery. 
Usually there is no internervous plane \& gluteus maximus (innervated by inferior gluteal nerve) muscle split is stopped when first nerve branch to upper part of muscle is encountered the superior gluteal artery supplies proximal $1 / 3$ while the inferior gluteal artery supplies distal $2 / 3$ of muscle [8]. The procedure is carried usually under spinal, epidural or some time general anaesthesia with the patient well supported in lateral position 10 to $15 \mathrm{~cm}$ curved skin incision one inch posterior to posterior edge of greater trochanter $\& 7 \mathrm{~cm}$ above and posterior to GT curving posterior to the GT and continue down the shaft of femur. Superficial dissection is carried with fascia lata sharp incision parallel to skin wound to uncover vastus lateralis distally which may either be split or elevated from lateral intermuscular septum then split fibers of gluteus maximus in proximal incision. With internally rotated hip (stretching short external rotators) place stay suture in piriformis and obturator internus tendon then detached it close to their femoral insertion \& reflect them backwards to protect sciatic nerve. Then Incise capsule with longitudinal or T-shaped incision \& dislocate hip with internal rotation. The wound can extend proximally towards iliac crest for exposure of ilium \& distally down line of femur down to level of $\mathrm{knee}^{3}$ The structure at risk include the Sciatic nerve located along posterior surface of quadratus femoris $\&$ prevented by extending the hip and flex knee with the use of proper gentle retraction and releasing of short external rotators (obturator internus) posteriorly to protect the sciatic nerve from traction. The Inferior gluteal artery it may injure when it leaves pelvis below piriformis or the First perforating branch of profunda femoris during release of gluteus maximus insertion. Other at risk structure includes femoral vessels, Superior gluteal artery and nerve, Quadratus femoris. ${ }^{8}$ The advantages of this approach include its reproducible anatomy and exposure, and the avoidance of the abductor musculature. The major disadvantages include the need to perform the procedure in the lateral decubitus position, limited extensibility, and difficulty in knowing the exact position of the pelvis during reconstruction. ${ }^{3}$

In comparison to other approaches; the dislocation is higher as founded by Bush JB, Wilson MR. ${ }^{9}$ Where dislocation rate is higher in posterior that anterior approach $(4.5 \%$ versus $0.0 \%)$. While other describe the marked reduction in the rates fallowing tissue repair $(6.38 \% \text { versus } 0 \%)^{7,3}$ The Muscles \& soft tissues damage as indicated with serum CK is 5.5 more in posterior than minimally invasive anterior total hip arthroplasty approach. ${ }^{1}$ The anterior approach had the early hospital discharge, good rehabilitation, \& fewer readmission rates. ${ }^{10,11}$ Where subjects operated with the posterior approach reported significantly higher stiffness than anterior subjects, but similar pain and function. ${ }^{12}$

Total hip arthroplasty was associated with a slightly higher risk of dislocation and general complications compared to hemiarthroplasty. ${ }^{13}$ Although surgeons have used these statements to defend their preferred surgical approach, a more recent metanalysis and the Cochrane database find not sufficient data in the literature to support either one of the above statements. ${ }^{14}$

\section{Dislocation and subluxation}

Dislocation of a THA is defined by the loss of contact between the femoral head and Acetabular component that requires intervention to relocate the joint. While Subluxation is refers to transient loss of contact that usually is self-reduced ${ }^{15}$ The incidence of dislocation fallowing total hip arthroplasty is range from $1.36 \%$ to $5 \%,{ }^{16-23}$ while posterior approach has dislocation rate range from $2 \%$ to $6.4 \% 0^{2,24,25}$ this rate was significantly reduced after soft tissue repair to $2 \%$ or less, ${ }^{22,24-26}$ or even $0.0 \% .^{26,27}$ The dislocation rate after primary THA was $1.1 \%$ and the re-dislocation rate after a first occurrence was as high as $39 \% .^{23}$
Numerous factors influence the rate of dislocation after THR such as greater age, ${ }^{27,28}$ previous surgery to the affected hip, ${ }^{16,29-}$ 33 concomitant neurological deficiencies, ${ }^{26,30,31}$ excessive alcohol intake $e^{33,35}$ and non-union of the greater trochanter ${ }^{33,36,37}$ All cause softtissue imbalance and increase the risk of dislocation. Some authors have reported a higher rate of dislocation when using a posterior surgical approach ${ }^{22,36,37}$ and Kristiansen et al. ${ }^{38}$ noted less acetabular version with this approach. Soft-tissue imbalance and malposition are thought to be the two main causes of dislocation. ${ }^{14,39}$ Malposition has long been recognised as an important cause of dislocation..$^{20,29,38,40-42}$ The most commonly recognized cause of failure, however, is orientation of the acetabular component ${ }^{21} \&$ excessive femoral antiversion. ${ }^{43,44}$ However By contrast, McCollum \& Gray ${ }^{40}$ asserted that orientation of the femoral component is less critical than orientation of the acetabular component. Despite no earlier clinical study, DiGioia et al. ${ }^{45}$ highlighted the necessity to position the cup to an accuracy which was better than $10^{\circ}$. An antiversion of $15^{\circ}$ and an abduction of $45^{\circ}$ showed the lowest risk for dislocation. Dorr et al..$^{30}$ stated that one of the most common technical errors which resulted in recurrent dislocation was incorrect antiversion of the acetabular component. They suggested that this could be avoided by using anatomical landmarks at the time of surgery. Variations in positioning of the patient on the operating table can lead to inaccurate orientation of the acetabular component at the time of surgery. ${ }^{21,45}$

Impingement of the neck of the femoral component on the margin of the socket of the cup may tend to lever the head out of the cup serves as a fulcrum to dislocate the hip. It may sometime occur on the margin of the socket $\&$ this mainly either due to use of small head ${ }^{14,46}$ skirted head, or modular acetabular liners. Also the greater trochanter if enlarged or distorted because of previous surgery or as a result of the disease process may cause impingement \& if femoral offset has not been adequately restored. ${ }^{14}$ Most dislocations occur within the first 3 months after surgery. The dislocation often is precipitated by malpositioning of the hip at a time when the patient has not yet recovered muscle control and strength. Late dislocations can be caused by progressive improvement in motion after surgery. Impingement caused by component malposition or retained osteophytes may not become manifest until extremes of flexion and adduction are possible. Late dislocations are more likely to become recurrent and require surgical intervention. ${ }^{14}$

Surgical approach for total hip replacement has remained controversial. ${ }^{47}$ The choice of surgical approach affects the rate of postoperative dislocation. Woo \& Morrey ${ }^{36}$ found the dislocation rate to be $5.8 \%$ when a posterolateral approach was used compared with $2.3 \%$ when an anterolateral approach was used. Fackler \& Poss $^{28}$ reported a $2.4 \%$ dislocation rate with the posterolateral approach. ${ }^{14}$ There is a tendency to retrovert the socket when total hip arthroplasty is done through a posterolateral approach. ${ }^{14}$ Posterior approach is known to give less blood loss, to shorten operation time and to allow optimal component positioning. It is considered an easy access, with less soft tissue dissection than other hip approaches, especially direct lateral, and is associated with fewer gait problems as well. ${ }^{47}$ It associated with a higher percentage of posterior dislocation $3.2 \%$ to $4.2 \%$ of the implanted hip has been observed with the posterior approach. ${ }^{14,48-50}$ Nevertheless, re-attachment of the posterior capsular flap and tendons (of piriformis and obturator internus) to the greater trochanter have reduced the incidence of dislocation to $0.7 \%$. Further, most dislocations happen to be posterior and a majority occur within the first six months of implantation. ${ }^{51}$ 
Posterior soft tissue repair is a well known procedure in total hip arthroplasty. In 1990, Hedley et al. reported on the routine reattachment of the posterior capsule and the short external rotator muscles in one layer to the greater trochanter using multiple sutures. Only two traumatic dislocations were noted in 259 hips for a minimum follow-up of one year. The reported dislocation rate was $0.4 \%{ }^{52}$ Many reports have shown the advantage of posterior soft tissue repair in reducing the dislocation rate fallowing posterior approach. ${ }^{2,24,53-56}$ If capsule (and not the rotators) is sutured to the medius tendon (not to bone), creating an elastic end point that is less likely to disrupt during the healing process result in reduction of rate from $4 \%$ to $0.4 \% .{ }^{57}$ Cadaveric study compare no repair, piriformis only repair, and a transosseous capsular repair found that transosseous repair (using drill holes in the greater trochanter) resulted in a torsion strength four times greater than the no repair group and two times greater than the soft tissue piriformis group. ${ }^{24}$ In 2001 , White et al. ${ }^{58}$ developed a technique for creating a posterior capsular flap in which the short external rotator muscles and posterior capsule were not separated, and the posterior capsular flap was repaired and sutured back to the greater trochanter. The incidence of posterior hip dislocation was reported to be $0.7 \%$ (three out of 437 hips) for this study ${ }^{58}$ Ultrasonography can be used to effectively assess the integrity of the posterior repair after total hip arthroplasty. The posterior structures were intact in the majority of patients 3 months after total hip arthroplasty (89\%). ${ }^{59}$ An excessive pain on motion of the hip, any abnormal internal or external attitude of the hip with limited active and passive motion, or shortening of the limb is suggestive of dislocation. Roentgenograms of the hip should be obtained. Management extent from simple close reduction to surgical revision. ${ }^{14}$ Factors found to be associated with revision included younger age, greater comorbidity, a diagnosis of avascular necrosis (AVN) as compared to osteoarthritis (OA), low surgeon volume, and larger femoral head size. Male sex was associated with revision due to aseptic loosening and infection. Longer operating time was associated with revision due to infection. Smaller femoral head size was associated with revision due to dislocation. ${ }^{16}$

\section{Objective}

\section{General objective}

a. To determine dislocation rate following total hip arthroplasty using posterior approach and intra-osseous repairs of short rotators.

\section{Material \& methods}

Prospective, descriptive, hospital based longitudinal study conducted in Elribat University Hospital from June 2013 to 2014 included all total hip arthroplasty patients operated using posterior approach and intra-osseous repair of short rotator. Data collected by contact the patient 6 month postoperative using Questionnaire \& Harris hip. The data analyzed is by Excel (office 2007).

\section{Inclusion criteria}

a. Total hip arthroplasty.

b. Using intra-osseous repair of short rotators to the greater trochanter.

\section{Exclusion criteria}

a. Hemi-arthroplasty.

b. Surgery without repair or with soft tissue repair other than interaosseous one.

\section{Procedure}

With the patient in lateral position (left lateral or right lateral) \& $30^{\circ}$ flexion to both hip \& knee, the hip joint is approach via posterior approach (of Moore) with longitudinal splitting of deep fascia. Then the joint approach posteriorly with isolation of sciatic nerve $\&$ anterior retraction of posterior border of gluteus medius followed by detachment of short rotator muscles \& capsule from the proximal femur as one layer, where femur head \& acetabulum are clearly visible. Femoral head removed \& acetabulum prepared with insertion of the cup (cemented or noncemented) parallel to the transverse acetabular ligament with combined antiversion of 20$40^{\circ}$. After that femur prepared \& stem was inserted (cemented or noncemented). Joint irrigated with 6 liters of gentamycine loaded saline, then reduction was done with continues traction \& external rotation. Stability is checked intra-operative with posterior push over $90^{\circ}$ knee \& hip flexion. Finally the reflected flab (capsule \& external rotatory muscles) was reattached to greater trochanteric drill- pit holes two using size two nylon sutures with limb kept in external rotation during the repair.

Closed system suction drain was put inside. Fascia and skin closed with interrupted suture of vicryle \& nylon respectively. First post-operative day drain removed \& patient mobilized with full weight bearing as tolerated using walking frame. Patient discharged according to unite policy, sutures removed two week later \& patient put in regular follow up.

\section{Results}

\section{General results}

The study includes 31 hips. Four patients were lost to follow up due to; death (cardiac disease 3 rd week post-operative), deep infection ( $7^{\text {th }}$ post-operative day) \& loss of contact. So the total remaining number were 27 hips with; 17 male $(62.96 \%) \& 10$ female $(37.04 \%)$. The patient's age ranges from 25 to 75 years ( 54.67 year). Operated side is almost equal; 14 right (51.85\%) \& 13 left (48.15\%) hip, while primary THA were $17(62.96 \%) \&$ revision THA were $10(37.04 \%)$. None cemented implants were $4(14.81 \%)$ compared to 23 cemented one $(85.19 \%)$. The preoperative Harris hip score were poor $(<70)$ for all patients. (Figures 1-5). The Frequency of indications for THA among the patients are vary with AVN of the femoral head is the commonest one fallowed by revision of aseptic losing of AM (Table 1). All operated patient show no dislocation, \& the frequency of other complication is represented in Figures 6 \& 7. Harris hip score is improving from poor Preoperative score is for all patients to an average of excellent postoperative score (Tables $2 \& 3$ ) (Figure 8).

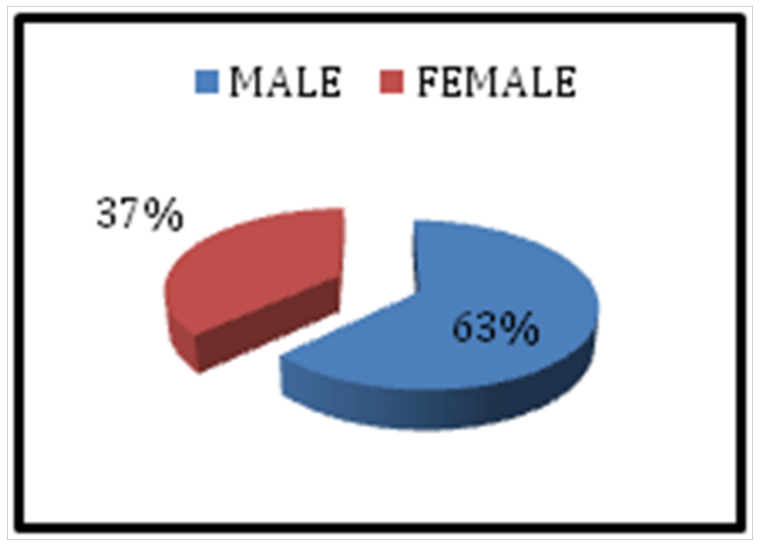

Figure I Gender distribution. 


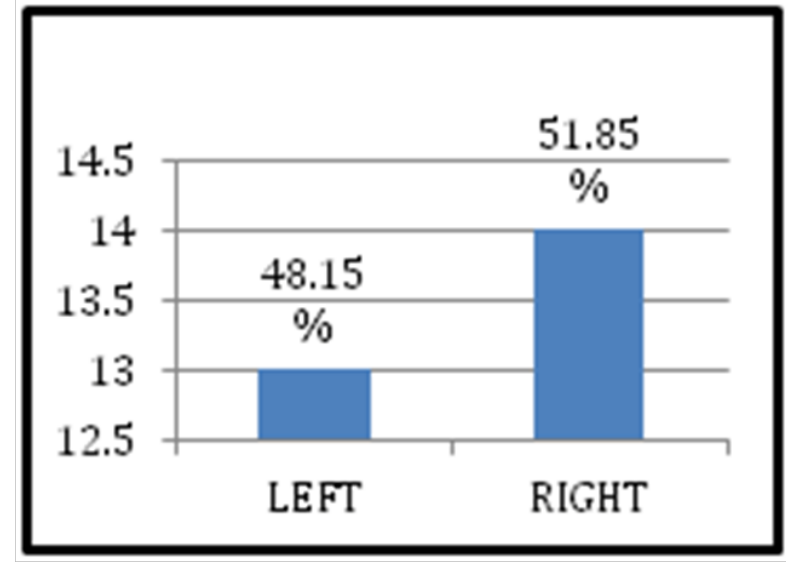

Figure 2 Joint distribution.

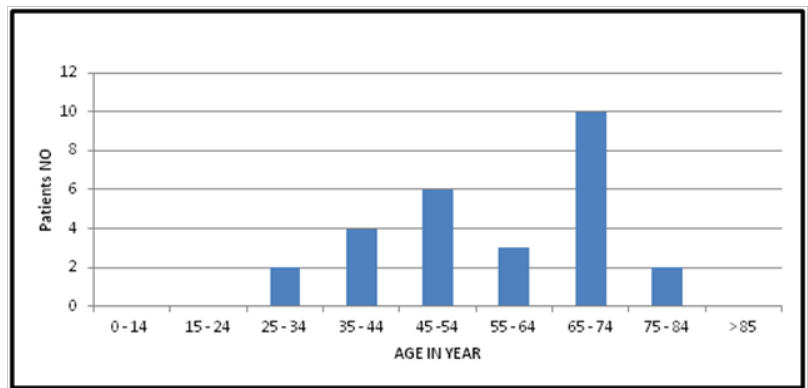

Figure 3 Age distributions.

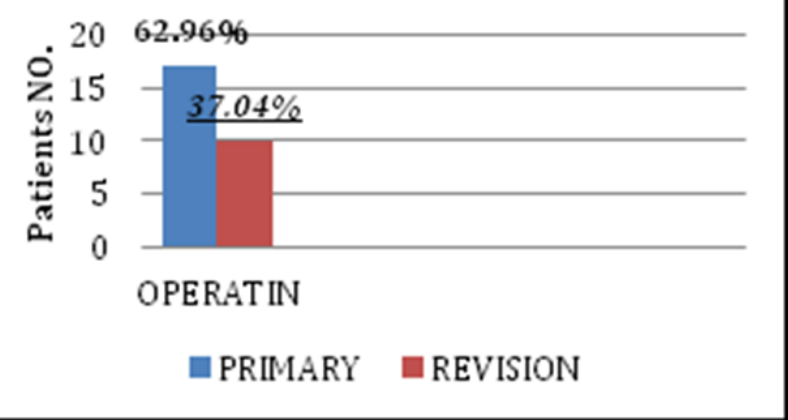

Figure 4 Type of surgery.

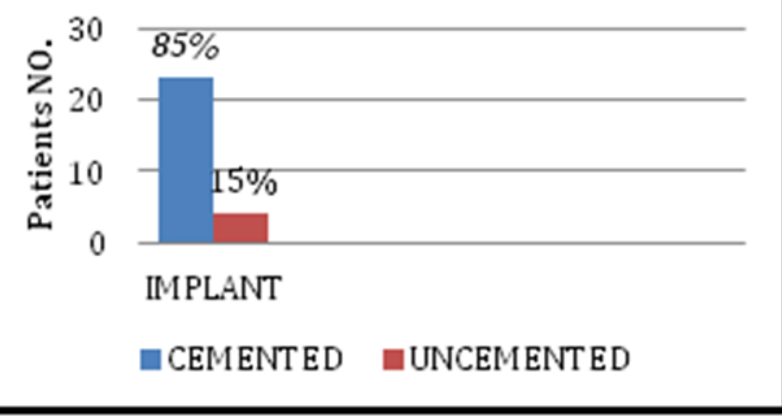

Figure 5 Type of implants.

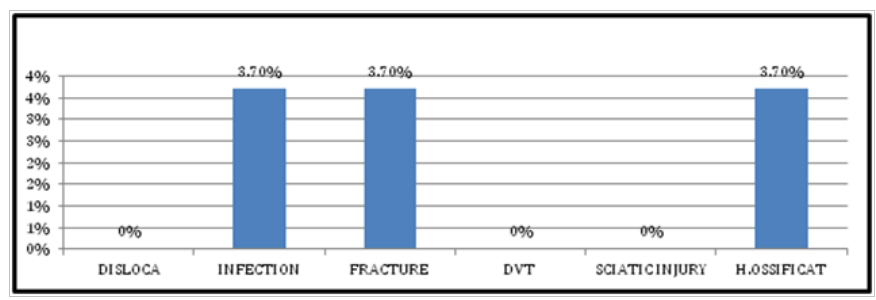

Figure 6 Frequency of postoperative complications.

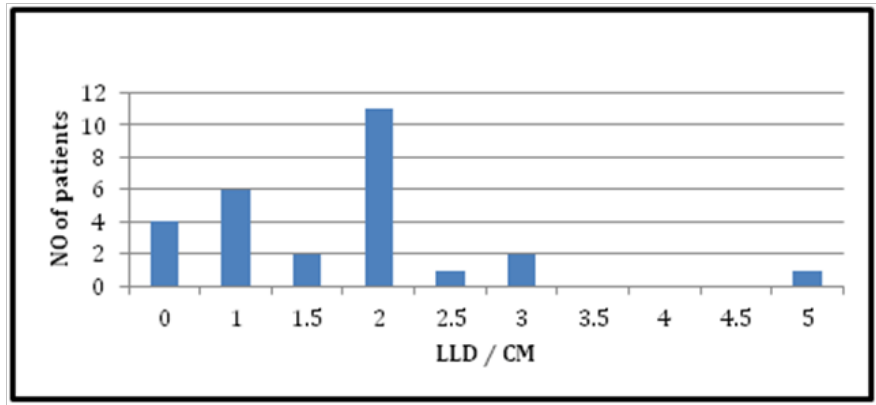

Figure 7 Frequency of leg lennght discripancies.

Table I Study indications for THA

S.No Indication

I A Vascular Necrosis (AVN)

2 A Septic Loosening of AM

of $A M$

Neglected Trans-Cervical Fracture

Dynamic Hip Screw (DHS)

Gun Shot

Neglected Acetabular Fracture

Revision;Anterior THA

Osteo-Arthritis (OA)

Total

Patient No Percentage (\%)

$10 \quad 37 \%$

$6 \quad 22 \%$

$3 \quad 11 \%$

$27 \%$

$3 \quad 11 \%$

I $4 \%$

$4 \%$
$4 \%$

$4 \%$

27

$100 \%$

Table 2 Harris hip score

\begin{tabular}{llll}
\hline & Range & Average Range & Average Score \\
\hline Pre-Op. HHS & $0.00-45.05$ & 25.26 & Poor $(<70)$ \\
Post-Op. HHS & $75-99.7$ & 91.38 & Excellent $(\geq 90)$ \\
\hline
\end{tabular}

Table 3 Distribution of harris hip score

\begin{tabular}{lllllllll}
\hline & \multicolumn{2}{l}{ Poor $(<\mathbf{7 0})$} & \multicolumn{2}{l}{ Fair (70 - 79) } & Good $(\mathbf{8 0}-\mathbf{8 9})$ & \multicolumn{2}{l}{ Excellent $(\geq \mathbf{9 0})$} \\
\hline HHS & Pts No & $\%$ & Pts No $\%$ & Pts No $\%$ & \multicolumn{2}{l}{ Pts No $\%$} \\
Preoperative & 27 & $100 \%$ & 0 & $0 \%$ & 0 & $0 \%$ & 0 & $0 \%$ \\
Postoperative & 0 & $0 \%$ & $\mathrm{I}$ & $4 \%$ & 7 & $26 \%$ & 19 & $70 \%$ \\
\hline
\end{tabular}

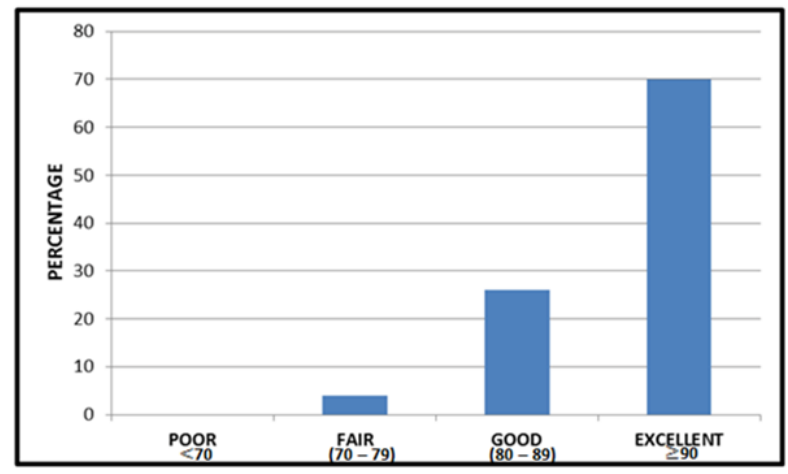

Figure 8 Postoperative harris hip score. 


\section{Discussion}

Hip joint is one of the large joint in the body, like any other joint where it affected with many diseases including inflammatory, degenerative, traumatic, congenital, etc. A diseased joint is very disabling, so when dealing with it we should take care in our approach to avoid ending with sever disability \& when needed, we may replace it with artificial one that is can do the function, but not as the biological one. Surgical approach for total hip replacement has remained controversial ${ }^{47}$ but posterior approach to the hip arthroplasty was criminated for long time to have a high dislocation rate. ${ }^{14,48-50}$ This was not the truth; as many reports raise the advantage of posterior soft tissue repair in reducing the dislocation rate fallowing posterior approach. ${ }^{53-60}$ Other study the deference between no repair, piriformis only repair, and a trans-osseous capsular repair; where trans-osseous repair (using drill holes in the greater trochanter) resulted in a torsion strength four times greater than the no repair group and two times greater than the soft tissue (piriformis only) group. ${ }^{54}$ Other study found if capsule (and not the rotators) is sutured to the medius tendon (not to bone) results in reduction of rate from $4 \%$ to $0.4 \%{ }^{57}$ So the fact that posterior approach of the hip has high dislocation rate is not true if it fallowed by good repair with trans-osseous been the best one. ${ }^{50-52,57-59}$

In our study all the patient operated with posterior approach with trans-osseous repair (using drill holes in the greater trochanter) \& there is no reported case of prosthesis dislocation. This is within the range of international figure of dislocation which range from 1.36 to $5 \%{ }^{15-22}$ If we compare it to other posterior approach studies with transosseous posterior capsular repair; it is similar to some reported figures $^{25,26} \&$ even less than others studies which report dislocation of $2 \% .^{21,23,24,37}$ There is no reported regional or local figure for comparison. Other reported post operative complications were comparable to international figure \& include; $0 \%$ for sciatic nerve injury, ${ }^{58,60,61} \&$ DVT. ${ }^{60,62,63}$ While is $3.73 \%$ for; infection, ${ }^{62}$ intra-operative fracture ${ }^{62-65}$ $\&$ hetero-topic ossification. ${ }^{4,66-67}$ One patient was died with cardiac shock \& represent $3.73 \%$ which is also comparable to international figure. ${ }^{14,67}$

\section{Conclusion \& recommendation}

\section{Conclusion}

In this study there is no dislocation following total hip arthroplasty using posterior approach and adequate short rotator repaired with intra-osseous suture to greater trochanter, using strong suture (Ethibond five or size 2 Nylon).

There is a good postoperative rehabilitation with no abductors weakness as gluteus medius was completely preserved. The approach also provides adequate visualization of acetabulum, proper acetabular preparation, good cup orientation, and sciatic nerve protection \& assessment. So the preference of Harding approach over the posterior approach is depend on the surgeon experience, and almost always better to operate with that you are familiar with it.

\section{Recommendation}

1. Posterior approach is one of the good approaches to hip for THA $\&$ for better results we recommend that

a. Inter- osseous attachment of the short rotators \& capsule to greater trochanter holes.

b. Using of a strong sutures (Size 2 Nylon or Ethibond 5).

c. Put the hip in maximal external rotations during the repair. d. Always insure providing proper abductor tension.

2. The study limitation was small sample size \& relatively short duration.

3. Long term fallow up is recommended for final conclusion.

4. The study assesses the dislocation rate following THA via posterior approach so we recommend another study of hemiarthroplasty dislocation rate following the same approach.

\section{Acknowledgments}

None.

\section{Conflicts of inteest}

None.

\section{References}

1. Bergin PF, Doppelt JD, Kephart CJ et al. Comparison of minimally invasive direct anterior versus posterior total hip arthroplasty based on inflammation and muscle damage markers. J Bone Joint Surg Am. 2011;93(15):1392-1398

2. Tsai SJ, Wang CT, Jiang CC The effect of posterior capsule repair upon post-operative hip dislocation following primary total hip arthroplasty. BMC Musculoskelet Disord. 2008;9:29.

3. Moussallem CD, Hoyek FA, Lahoud JC Incidence of piriformis tendon preservation on the dislocation rate of total hip replacement following the posterior approach: a series of 226 cases. J Med Liban. 2012;60(1):19-23.

4. Mark Miller, Stephen Thompson Jennifer Hart (2012) Review of Orthopaedics. (6th edn), pp. 896.

5. Solomon L, Warwick D, Nayagam S (2010) Apley's system of orthopaedics and fracture. (9th edn), CRC Press, UK, pp. 992.

6. Hip replacement history.

7. Mulliken BD, Rorabeck CH, Bourne RB, Nayak N (1995) The surgical approach to total hip arthroplasty: complications and utility of a modified direct lateral approach. Iowa Orthop J 15: 48-61.

8. Schweppe ML, Seyler TM, Plate JF, Swenson RD, Lang JE (2013) Does Surgical Approach in Total Hip Arthroplasty Affect Rehabilitation, Discharge Disposition, and Readmission Rate? Surg Technol Int 23: 219-227.

9. Martin CT, Pugely AJ, Gao Y, Clark CR (2013) A comparison of hospital length of stay and short-term morbidity between the anterior and the posterior approaches to total hip arthroplasty. J Arthroplasty 28(5): 849854

10. Maffiuletti NA, Impellizzeri FM, Widler K, Bizzini M, Kain MS, et al (2009) Spatiotemporal parameters of gait after total hip replacement: anterior versus posterior approach. Orthop Clin North Am 40(3): 407 415 .

11. Hopley C, Stengel D, Ekkernkamp A, Wich M (2010) Primary total hip arthroplasty versus hemiarthroplasty for displaced intracapsular hip fractures in older patients: systematic review. BMJ 340: c2332.

12. Bottner F, Pellicci PM (2006) Review: posterior soft tissue repair in primary total hip arthroplasty. HSS J 2(1): 7-11.

13. Canale T, James H Beaty (2008) Editorial assistance by Daugherty. $\mathrm{K}$ and Jones. L. Campbell's operative orthopaedics. (11th edn), Kim Murphy, Part III. Chap 7, China, pp. 392-428.

14. Padgett DE, Warashina H (2004) The unstable total hip replacement. Clin Orthop Relat Res (420): 72-79.

15. Mark D Miller (2008) Review Of Orthopaedics. (5th edn), pp. 709. 
16. Prokopetz JJ, Losina E, Bliss RL, Wright J, Baron JA, et al. (2012) Risk factors for revision of primary total hip arthroplasty: a systematic review. BMC Musculoskelet Disord 13: 251.

17. van Stralen GM, Struben PJ, van Loon CJ (2003) The incidence of dislocation after primary total hip arthroplasty using posterior approach with posterior soft-tissue repair. Arch Orthop Trauma Surg 123(5): 219222.

18. Khatod M, Barber T, Paxton E, Namba R, Fithian D (2006) An analysis of the risk of hip dislocation with a contemporary total joint registry. Clin Orthop Relat Res 447: 19-23

19. Lewinnek GE, Lewis JL, Tarr R, Compere CL, Zimmerman JR (1978) Dislocations after total hip-replacement arthroplasties. J Bone Joint Surg Am 60(2): 217-220.

20. Morrey BF (1992) Instability after total hip arthroplasty. Orthop Clin North Am 23(2): 237-248.

21. Phillips CB, Barrett JA, Losina E, Mahomed NN, Lingard EA, et al (2003) Incidence rates of dislocation, pulmonary embolism, and deep infection during the first six months after elective total hip replacement. J Bone Joint Surg Am 85-A(1): 20-26.

22. Suh KT, Park BG, Choi YJ (2004) A posterior approach to primary total hip arthroplasty with soft tissue repair. Clin Orthop Relat Res (418): 162-167.

23. Tarasevicius S, Robertsson O, Wingstrand $\mathrm{H}$ (2010) Posterior soft tissue repair in total hip arthroplasty: a randomized controlled trial. Orthopedics 33(12): 871.

24. Chiu FY, Chen CM, Chung TY, Lo WH, Chen TH (2000) The effect of posterior capsulorrhaphy in primary total hip arthroplasty: a prospective randomized study. J Arthroplasty 15(2): 194-199.

25. Weeden SH, Paprosky WG, Bowling JW (2003) The early dislocation rate in primary total hip arthroplasty following the posterior approach with posterior soft-tissue repair. J Arthroplasty 18(6): 709-713.

26. Woolson ST, Rahimtoola ZO (1999) Risk factors for dislocation during the first 3 months after primary total hip replacement. J Arthroplasty 14(6): 662-668.

27. Newington DP, Bannister GC, Fordyce M (1990) Primary total hip replacement in patients over 80 years of age. J Bone Joint Surg Br 72(3): 450-452.

28. Fackler CD, Poss R (1980) Dislocation in total hip arthroplasties. Clin Orthop Relat Res 151: 169-178.

29. Ali Khan MA, Brakenbury PH, Reynolds IS (1981) Dislocation following total hip replacement. J Bone Joint Surg Br 63-B(2): 214-218.

30. Dorr LD, Wolf AW, Chandler R, Conaty JP (1983) Classification and treatment of dislocations of total hip arthroplasty. Clin Orthop Relat Res 173: $151-158$

31. Paterno SA, Lachiewicz PF, Kelley SS (1997) The influence of patientrelated factors and the position of the acetabular component on the rate of dislocation after total hip replacement. J Bone Joint Surg Am 79(8): 1202-1210.

32. Lindberg HO, Carlsson AS, Gentz CF, Pettersson H (1982) Recurrent and non-recurrent Dislocation following total hip arthroplasty. Acta Orthop Scand 53(6): 947-952.

33. Callaghan JJ, Heithoff BE, Goetz DD, Sullivan PM, Pedersen DR, et al. (2001) Prevention of dislocation after hip arthroplasty: lessons from long-term followup. Clin Orthop 393: 157-162.

34. Carlsson AS, Gentz CF (1977) Postoperative dislocation in the Charnley and Brunswick total hip arthroplasty. Clin Orthop 125: 177-182.

35. Joshi A, Lee CM, Markovic L, Vlatis G, Murphy JC (1998) Prognosis of dislocation after total hip arthroplasty. J Arthroplasty 13(1): 17-21.
36. Woo RY, Morrey BF (1982) Dislocations after total hip arthroplasty. J Bone Joint Surg Am 64(9): 1295-1306.

37. Roberts JM, Fu FH, McClain EJ, Ferguson AB (1984) A comparison of the postero-lateral and anterolateral approaches to total hip arthroplasty. Clin Orthop Relat Res (187): 205-210.

38. Kristiansen B, Jorgensen L, Holmich P (1985) Dislocation following total hip arthroplasty. Arch Orthop Trauma Surg 103(6): 375-377.

39. García-Cimbrelo E, Munuera L (1992) Dislocation in low-friction arthroplasty. J Arthroplasty 7(2): 149-155.

40. McCollum DE, Gray WJ (1990) Dislocation after total hip arthroplasty: causes and prevention. Clin Orthop Relat Res (261): 159-170.

41. Yuan L, Shih C (1999) Dislocation after total hip arthroplasty. Arch Orthop Trauma Surg 119(5-6): 263-266.

42. Kohn D, Ruhmann O, Wirth CJ (1997) Dislocation of total hip endoprosthesis with special reference to various techniques. Z Orthop Ihre Grenzgeb 135(1): 40-44.

43. Turner RS (1994) Postoperative total hip prosthetic femoral head dislocations: incidence, etiologic factors, and management. Clin Orthop Relat Res (301): 196-204.

44. Ritter MA (1976) Dislocation and subluxation of the total hip replacement. Clin Orthop Relat Res (121): 92-94.

45. Digioia AM, Jaramaz B, Plakseychuk AY, Moody JE, Nikou C, et al. (2002) Comparison of a mechanical acetabular alignment guide with computer placement of the socket. J Arthroplasty 17(3): 359-364.

46. Plate JF, Seyler TM, Stroh DA, Issa K, Akbar M, et al. (2012) Risk of dislocation using large- vs. small-diameter femoral heads in total hip arthroplasty. BMC Res Notes 5: 553

47. Gulati A, Dwyer AJ, Shardlow DL (2008) The impact of posterior approach for total hip arthroplasty on early complications. Acta Orthop Belg 74(2): 200-205.

48. Kwon MS, Kuskowski M, Mulhall KJ, Macaulay W, Brown TE, et al. (2006) Does surgical approach affect total hip arthroplasty dislocation rates? Clin Orthop Relat Res 447: 34-38.

49. Masonis JL, Bourne RB (2002) Surgical approach, abductor function, and total hip arthroplasty dislocation. Clin Orthop Relat Res (405): 4653.

50. Ritter MA, Harty LD, Keating ME, Faris PM, Meding JB (2001) A clinical comparison of the anterolateral and posterolateral approaches to the hip. Clin Orthop Relat Res (385): 95-99.

51. Fabeck L, Farrokh D, Tolley M, Descamps PY, Gebhart M, et al. (1999) A method to measure acetabular cup anteversion after total hip replacement. Acta Orthop Belg 65(4): 485-491.

52. Hedley AK, Hendren DH, Mead LP (1990) A posterior approach to the hip joint with complete posterior capsular and muscular repair. J Arthroplasty 5 Suppl: S57-S66.

53. Mihalko WM, Whiteside LA (2004) Hip mechanics after posterior structure repair in total hip arthroplasty. Clin Orthop Relat Res (420): 194-198.

54. Sioen W, Simon JP, Labey L, Van Audekercke R (2002) Posterior transosseous capsulotendinous repair in total hip arthroplasty. J Bone Joint Surg Am 84-A(10): 1793-1798.

55. AK Kapoor, I Rafiq, A Hoad Reddick, MV Hemmady, AK Gambhir, et al. (2008) Early rate of dislocation after hip arthroplasty using posterior approach with capsulorraphy and size $22 \mathrm{~mm}$ head. J Bone Joint Surg Br 90-B(Suppl 3): 545.

56. Pellicci PM, Bostrom M, Poss R (1998) Posterior approach to total hip replacement using enhanced posterior soft tissue repair. Clin Orthop Relat Res (355): 224-228. 
57. Dixon MC, Scott RD, Schai PA, Stamos V (2004) A simple capsulorrhaphy in a posterior approach for total hip arthroplasty. J Arthroplasty 19(3): 373-376.

58. White RE Jr, Forness TJ, Allman JK, Junick DW (2001) Effect of posterior capsular repair on early dislocation in primary total hip replacement. Clin Orthop Relat Res (393): 163-167.

59. Su EP, Mahoney CR, Adler RS, Padgett DE, Pellicci PM (2006) Integrity of repaired posterior structures after THA. Clin Orthop Relat Res 447: 43-47.

60. Hurd JL, Potter HG, Dua V, Ranawat CS (2006) Sciatic nerve palsy after primary total hip arthroplasty. a new perspective. J Arthroplasty 21: 796-802.

61. Howie C, Hughes H, Watts AC (2005) Venous thrombo-embolism associated with hip and knee replacement over a ten-year period : a population-based study. J Bone Joint Surg Br 87(12): 1675-1680.

62. O'Reilly RF, Burgess IA, Zicat B (2005) The prevalence of venous thromboembolism after hip and knee replacement surgery. Med J Aust 182(4): 154-159.
63. Cameron HU (2004) Intraoperative hip fractures : ruining your day. J Arthroplasty 19(4 Suppl 1): 99-103.

64. Kocic M, Lazovic M, Mitkovic M, Djokic B (2010) Clinical significance of the heterotopic ossification after total hip arthroplasty. Orthopedics 33(1): 16 .

65. S Eggli, A Woo (2001) Risk factors for heterotopic ossification in total hip arthroplasty. Archives of Orthopaedic and Trauma Surgery 121(9): 531-535.

66. Regis D, Sandri A, Sambugaro E (2013) Incidence of Heterotopic Ossification after Surface and Conventional Total Hip Arthroplasty: A Comparative Study Using Anterolateral Approach and Indomethacin Prophylaxis. Biomed Res Int 2013: 293528.

67. Mantilla CB, Horlocker TT, Schroeder DR, Berry DJ, Brown DL (2002) Frequency of Myocardial Infarction, Pulmonary Embolism, Deep Venous Thrombosis, and Death following Primary Hip or Knee Arthroplasty. Anesthesiology 96(5): 1140-1146. 